\title{
The association of dietary inflammatory index with urinary risk factors of kidney stones formation in men with nephrolithiasis
}

\author{
Niloofarsadat Maddahi ${ }^{1}$, Habib Yarizadeh', Seyed Mohammad Kazem Aghamir ${ }^{2}$, Shahab Alizadeh', \\ Mir Saeed Yekaninejad ${ }^{3}$ and Khadijeh Mirzaei ${ }^{1^{*}}$ (D)
}

\begin{abstract}
Objective: Inflammation plays a leading role in the pathogenesis of nephrolithiasis. The association of the dietary inflammatory index (DII) with urinary lithogenic factors is unclear. This study aimed to evaluate the relation of DII to urinary risk factors of kidney stones formation.

Results: Of 264 participants, $61.4 \%(n=162), 72 \%(n=190), 74.6 \%(n=197), 68.6 \%(n=181)$, and $80.3 \%(n=212)$ had hyperoxaluria, hypercreatininuria, hypercalciuria, hyperuricosuria, hypocitraturia, respectively. There was a significant increasing trajectory in urinary calcium, uric acid, and creatinine as well as a decreasing trend in urinary citrate across tertiles of Dll score (all $P=\leq 0.001$ ). After multivariate adjustment for energy intake, age, physical activity and body mass index, high DII scores were associated with elevated odds of having hypercreatininuria $(\mathrm{OR}=2.80,95 \% \mathrm{Cl}$ : $\left.1.10-7.12, P_{\text {trend }}=0.04\right)$, hypercalciuria $\left(\mathrm{OR}=7.44,95 \% \mathrm{Cl}: 2.62-21.14, \mathrm{P}_{\text {trend }} \leq 0.001\right)$, hyperuricosuria $(\mathrm{OR}=2.22,95 \% \mathrm{Cl}$ : $\left.1.001-4.95, P_{\text {trend }}=0.05\right)$, and hypocitraturia $\left(O R=5.84,95 \% \mathrm{Cl}: 2.14-15.91, P_{\text {trend }} \leq 0.001\right)$. No association was identified between DIl and hyperoxaluria.
\end{abstract}

Keywords: Dietary inflammatory index, Kidney stones, Hypercalciuria, Hypocitraturia, Hyperoxaluria, Hyperuricosuria, Hypercreatinuria

\section{Introduction}

Nephrolithiasis is one of the most prevalent urologic disorders and impose a substantial burden on human health globally [1]. The high recurrence rate of kidney stones is yet unsolved $[2,3]$.Thus, there is an urgent need to target modifiable risk factors to prevent the development and recurrence of renal stones.

Higher urinary excretions of oxalate, calcium, creatinine, and uric acid as well as lower excretions of citrate are potential modifiable urinary lithogenic risk factors

\footnotetext{
*Correspondence: mina_mirzaei101@yahoo.com

${ }^{1}$ Department of Community Nutrition, School of Nutritional Sciences and Dietetics, Tehran University of Medical Sciences (TUMS), Tehran, P.O. Box: 14155-6117, Iran

Full list of author information is available at the end of the article
}

involved in the formation of kidney stones [4-6]. Inflammation is also another mechanism which plays a leading role in the pathogenesis of nephrolithiasis [7]. Dietary modifications toward decreasing inflammation may have a potential to prevent kidney stones or their recurrence. Several micronutrients or foods such as magnesium, vitamin $\mathrm{E}$, vitamin $\mathrm{C}$, carotenoids, fruits, and fish had an anti-inflammatory impact [8-11]. In contrast, simple sugars, red meats, high-fat dairy products, and refined grains are associated with elevated inflammatory markers [12]. Nevertheless, nutrients or foods are not consumed separately but as part of the whole diet [13-15]. The Dietary Inflammatory Index (DII) is developed to measures the overall inflammatory potential of diets [16], which has been recognized to be related to the biomarkers of inflammation [17]. A proinflammatory diet has 
been found to be related to the reduced kidney function [18]. However, there is no study investigating the relation of DII to urinary lithogenic factors. Therefore, this study aimed to assess the association of DII with hypercalciuria, hypocitraturia, hyperoxaluria, hyperuricosuria, and hypercreatinuria in patients with nephrolithiasis.

\section{Main text \\ Methods \\ Subjects}

This cross-sectional study was performed on a total of 264 stone former men (aged 18- 89 years) in Tehran, Iran in 2016. Participants were recruited from the Urology Research Center of Sina Hospital, Tehran, Iran. Inclusion criteria for this study were having a history of kind stone formation and age $\geq 18$ years. People with a history of, thyroid disease, fatty liver disease, malignancy, stroke, diabetes, cardiovascular disease, and hypertension were excluded. Participants who were on medications such as corticosteroids, diuretics, anti-cancer drugs, multivitamins, potassium citrate, calcium, and vitamin D or $\mathrm{C}$ supplements were not eligible for this study. Furthermore, all alcohol drinkers and drugs abusers were excluded. Patients were included in the study after signing written informed consents.

\section{Dietary assessment}

Usual food intake of patients during the previous year was measured by a validated semi-quantitative 168 -item food frequency questionnaire) FFQ([19]. DII was calculated using the method reported by Shivappa et al. [20]. The DII is based on 1943 scientific papers scoring 45 food parameters based on whether they elevated $(+1)$, reduced $(-1)$ or had no impact $(0)$ on six inflammatory biomarkers [C-reactive protein, interleukin (IL)-1 beta, IL-10, IL-4, IL-6, and tumor necrosis factor-alpha). As mentioned, Shivappa et al. calculated DII according to the 45 food parameters. As dietary patterns of different populations are different with each other, some food parameters used in the study by Shivappa may not be available in different FFQs. Hence, researchers calculate DII according to available foods in the FFQ by modification of the method used by Shivappa. et al. [21]. In the current study, the DII score was calculated using the corresponding 32 food parameters available from the FFQ used in our study. This approach has been used broadly in the previous studies [21]. The DII score was calculated with the use of the corresponding 32 nutrients or food parameters available from the FFQ, including energy, protein, total fat, carbohydrate, dietary fiber, mono-unsaturated fatty acids, n-3 fatty acids, n- 6 fatty acids, poly-unsaturated fatty acids, saturated fatty acids, cholesterol, trans fatty acids, vitamin A, thiamin, niacin, riboflavin, Vitamin B-6, folate, vitamin B-12, vitamin E, vitamin C, Vitamin D, b-carotene, iron, magnesium, zinc, selenium as well as caffeine, onion, green/black tea, paper, and garlic. The inflammatory effect scores for dietary components used for calculation of DII in this study are reported in Additional file 1: Table S1. To calculate the DII score for each participant, the mean intake of each nutrient or food parameter was standardized by subtracting mean global intake of food items from the actual individual's intake and dividing it by the global SD to create a $\mathrm{z}$-score. $Z$-score is used to express an individual's exposure relative to the standard global exposure. This approach both anchors the individual's exposure to a robust range of dietary patterns in a variety of cultural traditions and obviates completely the problem of noncomparability of units because the $Z$-scores is independent of the units of measurement. These z-scores then were converted to proportions and centered by multiplying values by 2 and subtracting 1 to normalize the scoring system and to avoid skewness. The centered percentile values for food items were then multiplied by the corresponding food item-specific inflammatory effect scores to obtain the food item-specific DII scores. Calculation of DII for carbohydrate intake in a participant in our study as an example for DII calculation is presented in Additional file 1: Table S2; similar approach was followed for the calculation of DII for other nutrients. Information about global daily mean intake, standard deviation for global intake, and overall inflammatory effect score of all nutrients/food items used for DII calculation is reported in the study by Shivappa et al. [20]. The overall DII score for each individual was calculated by summing food item-specific DII scores [20]. Higher DII scores indicate a more pro-inflammatory diet, while lower DII scores indicate a more anti-inflammatory diet.

\section{Measurements of study outcomes}

The 24-h urine samples were collected from all participants and urine was analyzed using an AutoAnalyzer as described previously [22]. Hyperoxaluria was defined as the urinary oxalate $>40 \mathrm{mg} / \mathrm{day}$, hypocitraturia as urinary citrate of $<450 \mathrm{mg} /$ day, hyperuricosuria as urinary uric acid over $0.8 \mathrm{~g} /$ day, hypercreatininuria as urinary creatinine of $>24 \mathrm{mg} /$ day, and hypercalciuria as a urinary calcium $\geq 250 \mathrm{mg} /$ day [22].

\section{Measurement of other variables}

General Information was obtained using interview. Physical activity was measured using of the International Physical Activity Questionnaires (IPAQ) [23]. Body weight was measured in minimal clothing after removal of shoes by a digital scale (Seca, Germany) with a precision about $0.1 \mathrm{~kg}$. Height of individuals was assessed in 
standing position, without shoes, using a calibrated stadiometer (Seca, Germany) to the nearest $0.1 \mathrm{~cm}$. BMI was calculated as weight divided by the square of height $(\mathrm{kg} /$ $\mathrm{m} 2$ ).

\section{Statistical analyses}

DII was categorized into tertiles: T1 $(-3.72$ to -0.74$)$; T2 ( -0.73 to 0.92$)$; T3 (0.93 to 3.99 ). Analysis of variance (ANOVA) and Chi square tests were used to compare continuous and nominal/ordinal variables across tertiles of DII, respectively. Continuous variables are reported as mean $\pm \mathrm{SE}$ and nominal/ordinal variables as frequency. Odds ratio (OR) and 95\% confidence interval (CI) for the relation of DII to study outcomes was calculated using the logistic regression analysis. Statistical significance was set at $p \leq 0.05$ for all tests. All analyses were undertaken using the statistical Package for Social Science (Version 22.0; SPSS Inc., Chicago IL, USA).

\section{Results}

Participants in the highest tertile of the DII had significantly higher total daily energy intake $(P=\leq 0.001)$ and lower physical activity $(\mathrm{P}=0.01)$ than those in the other tertiles. There was a significant increasing trajectory in urinary calcium $(\mathrm{P}=\leq 0.001)$, uric acid $(\mathrm{P}=\leq 0.001)$, and creatinine $(\mathrm{P}=\leq 0.001)$ and a decreasing trend in urinary citrate $(\mathrm{P}=\leq 0.001)$ across tertiles of DII score (Table 1$)$.

\section{DII score and urinary lithogenic factors}

In the crude model, it was found that higher adherence to the DII was significantly related to the increased odds of hypercreatininuria $(\mathrm{OR}=7.60,95 \% \mathrm{CI}$ : $3.28-17.61$, $\left.\mathrm{P}_{\text {trend }} \leq 0.001\right)$, hypercalciuria $\quad(\mathrm{OR}=10.45, \quad 95 \% \mathrm{CI}$ :

Table 1 Characteristics of the study participants across tertiles of the DII score

\begin{tabular}{|c|c|c|c|c|c|}
\hline & \multirow{2}{*}{$\begin{array}{l}\text { Total } \\
\mathrm{N}=264\end{array}$} & \multicolumn{4}{|c|}{ Dietary inflammatory index score } \\
\hline & & Tertile $1(n=88)$ & Tertile $2(n=88)$ & Tertile $3(n=88)$ & $P$ value \\
\hline Age (year) & $42.68 \pm 0.78$ & $41.58 \pm 1.31$ & $43.83 \pm 1.38$ & $42.64 \pm 1.37$ & 0.50 \\
\hline Height (cm) & $173.52 \pm 0.47$ & $173.18 \pm 0.78$ & $173.56 \pm 0.86$ & $173.81 \pm 0.84$ & 0.86 \\
\hline Weight (kg) & $80.73 \pm 0.86$ & $80.93 \pm 1.60$ & $81.36 \pm 1.51$ & $79.92 \pm 1.39$ & 0.78 \\
\hline BMI (kg/m2) & $26.75 \pm 0.24$ & $26.94 \pm 0.47$ & $26.93 \pm 0.42$ & $26.37 \pm 0.37$ & 0.55 \\
\hline Physical activity score & $4851 \pm 453$ & $6654 \pm 991$ & $3413 \pm 669$ & $4486 \pm 611$ & 0.01 \\
\hline Energy intake (kcal/day) & $2435.86 \pm 35.44$ & $2205.91 \pm 44.04$ & $2380.07 \pm 59.24$ & $2721.61 \pm 66.05$ & $\leq 0.001$ \\
\hline $\begin{array}{l}\text { Urinary creatinine/kg weight } \\
(\mathrm{mg} / \text { day }) / \mathrm{kg}\end{array}$ & $26.50 \pm 0.49$ & $24.48 \pm 0.87$ & $25.51 \pm 0.92$ & $29.51 \pm 0.63$ & $\leq 0.001$ \\
\hline Urinary citrate (mg/day) & $350.94 \pm 9.69$ & $394.30 \pm 18.43$ & $358.42 \pm 17.25$ & $300.10 \pm 12.74$ & $\leq 0.001$ \\
\hline Urinary oxalate (mg/day) & $45.99 \pm 1.18$ & $44.73 \pm 2.12$ & $48.72 \pm 2.13$ & $44.52 \pm 1.88$ & 0.26 \\
\hline Urinary uric acid (g/day) & $857.61 \pm 17.09$ & $789.06 \pm 32.06$ & $823.79 \pm 28.21$ & $959.98 \pm 25.28$ & $\leq 0.001$ \\
\hline Urinary calcium (mg/day) & $329.02 \pm 8.02$ & $288.25 \pm 12.74$ & $325.11 \pm 15.52$ & $373.70 \pm 11.74$ & $\leq 0.001$ \\
\hline Job status & & & & & 0.22 \\
\hline Engineer/physician & 12 & 2 & 5 & 5 & \\
\hline Clerk & 57 & 20 & 19 & 18 & \\
\hline Student & 4 & 2 & 0 & 2 & \\
\hline Teacher & 4 & 2 & 0 & 2 & \\
\hline Self-employed & 77 & 28 & 28 & 21 & \\
\hline Retired & 47 & 14 & 19 & 14 & \\
\hline Worker & 60 & 20 & 14 & 26 & \\
\hline Unemployed & 3 & 0 & 3 & 0 & \\
\hline Marital status & & & & & 0.82 \\
\hline Married & 241 & 81 & 81 & 79 & \\
\hline Single & 23 & 7 & 7 & 9 & \\
\hline Education level & & & & & 0.68 \\
\hline Illiterate & 10 & 3 & 4 & 3 & \\
\hline$\leq$ Diploma & 190 & 59 & 66 & 65 & \\
\hline University degree & 64 & 26 & 18 & 20 & \\
\hline
\end{tabular}

Categorical variables are presented as frequency $(n)$, and continuous variables as mean \pm S.E. One-way ANOVA was used for continuous variables and person's Chi square test for categorical variables 
3.84-28.39, $\left.\mathrm{P}_{\text {trend }} \leq 0.001\right)$, hyperuricosuria $(\mathrm{OR}=4.40$, 95\%CI: $\left.2.16-8.94, \mathrm{P}_{\text {trend }} \leq 0.001\right)$, and hypocitraturia $\left(\mathrm{OR}=6.04,95 \% \mathrm{CI}: 2.35-15.55, \mathrm{P}_{\text {trend }} \leq 0.001\right)$. After multivariate adjustment for energy intake, age, physical activity and BMI, high DII scores were associated with elevated odds of having hypercreatininuria $(\mathrm{OR}=2.80$, 95\%CI: $\left.\quad 1.10-7.12, \quad \mathrm{P}_{\text {trend }}=0.04\right)$, hypercalciuria $\left(\mathrm{OR}=7.44,95 \% \mathrm{CI}: 2.62-21.14, \mathrm{P}_{\text {trend }} \leq 0.001\right)$, hyperuricosuria $\left(\mathrm{OR}=2.22,95 \% \mathrm{CI}: 1.001-4.95, \mathrm{P}_{\text {trend }}=0.05\right)$, and hypocitraturia $(\mathrm{OR}=5.84,95 \% \mathrm{CI}: 2.14-15.91$, $\left.P_{\text {trend }} \leq 0.001\right)$. The relation of DII to hypercreatininuria, hyperoxaluria, and hyperuricosuria was not significant after adjustment for carbohydrate, fiber and protein intake (Table 2).

We also evaluated the association of dietary protein and fiber intake on urinary risk factors (Table 3). After adjustment for covariates, dietary intakes of protein and fiber were slightly related to the decreased odds of hypocitraturia (Protein OR $=0.96,95 \% \mathrm{CI}$ : 0.93-0.98; fiber $\mathrm{OR}=0.96,95 \% \mathrm{CI}: 0.94-0.98)$ and hypercalciuria (Protein OR $=0.97,95 \% \mathrm{CI}$ : 0.95-0.99; fiber OR $=0.97$, 95\%CI: 0.95-0.99), while the intake of protein and fiber was not to associated with hypercreatininuria, hyperoxaluria, and hyperuricosuria.

\section{Discussion}

We revealed that, in stone former men, a diet with a high DII is significantly related to the increased odds of having hypercreatininuria, hypercalciuria, hyperuricosuria, and hypocitraturia, but not to hyperoxaluria.

It has been confirmed that kidney stone formers could be susceptible to recurrence in stones formation

Table 2 Univariate and multivariate logistic regression models for the relation of DII score to urinary risk factors of kidney stone formation

\begin{tabular}{|c|c|c|c|c|}
\hline & \multicolumn{4}{|c|}{ Dietary inflammatory index score } \\
\hline & Model 1 (Crude model) & Model 2 & Model 3 & Model 4 \\
\hline & Odds ratio $(95 \% \mathrm{Cl})$ & Odds ratio $(95 \% \mathrm{Cl})$ & Odds ratio $(95 \% \mathrm{Cl})$ & Odds ratio $(95 \% \mathrm{Cl})$ \\
\hline \multicolumn{5}{|l|}{ Hypercreatininuria } \\
\hline $\mathrm{T} 1$ & 1 & 1 & 1 & 1 \\
\hline $\mathrm{T} 2$ & $1.62(0.88-3.01)$ & $0.92(0.45-1.89)$ & $0.85(0.41-1.78)$ & $0.84(0.38-1.85)$ \\
\hline T3 & $7.60(3.28-17.61)$ & $3.10(1.23-7.81)$ & $2.80(1.10-7.12)$ & $2.21(0.78-6.28)$ \\
\hline$P$ value for trend & $\leq 0.001$ & 0.02 & 0.04 & 0.19 \\
\hline \multicolumn{5}{|l|}{ Hypocitraturia } \\
\hline $\mathrm{T} 1$ & 1 & 1 & 1 & 1 \\
\hline $\mathrm{T} 2$ & $1.60(0.81-3.17)$ & $1.53(0.75-3.11)$ & $1.69(0.82-3.49)$ & $1.16(0.55-2.44)$ \\
\hline T3 & $6.04(2.35-15.55)$ & $5.64(2.10-15.15)$ & $5.84(2.14-15.91)$ & $3.40(1.17-9.86)$ \\
\hline$P$ value for trend & $\leq 0.001$ & 0.001 & $\leq 0.001$ & 0.03 \\
\hline \multicolumn{5}{|l|}{ Hyperoxaluria } \\
\hline $\mathrm{T} 1$ & 1 & 1 & 1 & 1 \\
\hline $\mathrm{T} 2$ & $1.34(0.72-2.48)$ & $1.47(0.77-2.79)$ & $1.63(0.84-3.16)$ & $1.46(0.74-2.88)$ \\
\hline T3 & $0.86(0.47-1.58)$ & $0.99(0.52-1.90)$ & $1.12(0.57-2.19)$ & $0.87(0.41-1.83)$ \\
\hline$P$ value for trend & 0.64 & 0.95 & 0.78 & 0.69 \\
\hline \multicolumn{5}{|l|}{ Hyperuricosuria } \\
\hline $\mathrm{T} 1$ & 1 & 1 & 1 & 1 \\
\hline $\mathrm{T} 2$ & $1.69(0.92-3.12)$ & $1.08(0.55-2.13)$ & $1.20(0.59-2.42)$ & $0.94(0.45-1.95)$ \\
\hline $\mathrm{T} 3$ & $4.40(2.16-8.94)$ & $2.14(0.98-4.67)$ & $2.22(1.001-4.95)$ & $1.35(0.56-3.24)$ \\
\hline$P$ value for trend & $\leq 0.001$ & 0.06 & 0.05 & 0.53 \\
\hline \multicolumn{5}{|l|}{ Hypercalciuria } \\
\hline $\mathrm{T} 1$ & 1 & 1 & 1 & 1 \\
\hline $\mathrm{T} 2$ & $1.34(0.72-2.51)$ & $1.13(0.59-2.18)$ & $1.02(0.52-2.00)$ & $0.96(0.48-1.91)$ \\
\hline $\mathrm{T} 3$ & 10.45 (3.84-28.39) & $8.11(2.88-22.83)$ & $7.44(2.62-21.14)$ & $6.22(2.06-18.77)$ \\
\hline$P$ value for trend & $\leq 0.001$ & $\leq 0.001$ & $\leq 0.001$ & 0.003 \\
\hline
\end{tabular}

Model 2: adjusted for energy intake

Model 3: additionally adjusted for age, BMI, and physical activity

Model 4: adjusted for carbohydrate, fiber and protein intake 
Table 3 Multivariate logistic regression models for the relation of dietary fiber and protein intake, as continues variable, to urinary risk factors of kidney stone formation

\begin{tabular}{|c|c|c|c|c|}
\hline & \multicolumn{2}{|l|}{ Fiber } & \multicolumn{2}{|l|}{ Protein } \\
\hline & \multicolumn{2}{|c|}{ Odds ratio $(95 \% \mathrm{Cl})$} & \multicolumn{2}{|c|}{ Odds ratio $(95 \% \mathrm{Cl})$} \\
\hline & Model 1 & Model 2 & Model 1 & Model 2 \\
\hline Hypercreatininuria & $0.98(0.96-1.01)$ & $0.98(0.96-1.01)$ & $0.98(0.95-1.008)$ & $0.98(0.96-1.01)$ \\
\hline Hypocitraturia & $0.96(0.94-0.98)$ & $0.96(0.94-0.98)$ & $0.96(0.93-0.98)$ & $0.96(0.93-0.98)$ \\
\hline Hyperoxaluria & $0.98(0.96-1.006)$ & $0.98(0.96-1.005)$ & $1.00(0.98-1.02)$ & $1.00(0.98-1.02)$ \\
\hline Hyperuricosuria & $0.98(0.96-1.00)$ & $0.98(0.96-1.002)$ & $0.98(0.96-1.008)$ & $0.98(0.95-1.006$ \\
\hline Hypercalciuria & $0.97(0.95-0.99)$ & $0.97(0.95-0.99)$ & $0.97(0.94-0.99)$ & $0.97(0.95-0.99)$ \\
\hline
\end{tabular}

Model 1: adjusted for energy intake

Model 2: additionally adjusted for age, BMI, and physical activity

because of unhealthy dietary patterns [24]. Inconsistent with our finding, a study did not report any significant difference in creatinine across tertiles of DII in subjects with chronic kidney disease [25]. A randomized controlled trial study by Noori et al. [26] on recurrent stone formers showed that a DASH diet, which in contrast to a diet with a high DII, is featured by a high intake of whole grains, fruits, low-fat dairy products and vegetables, and a low intake of total fat, cholesterol, saturated fat, meat, and refined grains, is significantly associated with a decrease in calcium oxalate supersaturation and an increase in citrate excretion. Moreover, another study reported that greater adherence to the Mediterranean dietary pattern is related to the reduced risk for incident kidney stones [27]. The relationship between systemic inflammation and nephrolithiasis has been identified previously [7]. Since both DASH and Mediterranean diets attenuate inflammation [9, 28], the protective effects of these dietary patterns on kidney stones formation may be mediated, at least partly, by reducing systemic inflammation. A cross-sectional study conducted on diabetic patients also reported that higher intake of "vegetable and fish" dietary pattern is related to a lower creatinine rates [29]. Vegetables and fish, as components of DII, are identified to have antiinflammatory effects [30,31]. The DII is a tool to assess the overall impact of a diet on inflammatory potential [20], and is associated with markers of systemic inflammation including such as IL-6 [32], and CRP [17] [..]; IL- 6 and CRP are two of the inflammatory biomarkers considered in the calculation of DII [20]. It has been revealed that the DII score is inversely related to the Dietary Approaches to Stop Hypertension Score (DASH), Mediterranean Diet Score, and Healthy Eating Index-2010 [33, 34]. Taken together, these findings support that a likely mechanism for the relation of DII scores to hypercreatininuria, hypercalciuria, hyperuricosuria, and hypocitraturia could be explained by the higher systemic inflammation level among people following a pro-inflammatory diet.

Since DII positively depends on protein intake that is also a metabolic risk factor for hypercalciuria, hyperuricosuria, and hypocitraturia, and on contrary, dietary fiber has a negative impact on DII and is a factor that can reduce calcium absorption, we also adjusted the analysis for protein, carbohydrate, and fiber intake to differentiate the metabolic impact of DII from its pro-inflammatory impact. It was found that DII is related to hypercalciuria and hypocitraturia independent of dietary intake of protein, carbohydrate, and fiber, however, the relationship between DII and hyperuricosuria disappeared, showing that this association may be resulted from metabolic effects of DII. Nevertheless, protein and fiber intake was inversely associated with hypercalciuria and hypercalciuria.

\section{Conclusion}

In conclusion, this study found that a diet with high inflammatory property might be unfavorably associated with urinary risk factors of kidney stone formation in men with a history of nephrolithiasis.

\section{Limitation}

First, since the participants of the current study were limited to men, our findings may not be generalizable to women; therefore, it is essential to conduct such a study on women too. Third, causation cannot be inferred the cross-sectional design of the present investigation. Finally, the calculation of DII by FFQ has a potential recall bias for the evaluation of dietary intake. 


\section{Supplementary information}

Supplementary information accompanies this paper at https://doi. org/10.1186/s13104-020-05206-y.

Additional file 1: Table S1. Inflammatory effect scores for dietary components used for calculation of DII. Table S2. calculation of DII for carbohydrate intake in a participant in our study as an example for total DIl calculation.

\section{Abbreviations}

IPAQ: International physical activity questionnaires; DII: Dietary inflammatory index; PUFAs: Polyunsaturated fatty acids; CRP: C- reactive protein; FFQ: Food frequency questionnaire; ANOVA: Analysis of variance; OR: Odds ratio; $\mathrm{Cl}$ : Confidence interval; BMI: Body mass index.

\section{Acknowledgements}

We would like to thank the Tehran University of Medical Sciences. This work was supported by Tehran University of Medical Sciences (Grant ID1395.1046).

\section{Authors' contributions}

SMKA designed the research and collected the samples; NSM and SHA wrote the paper; HY and MSY analyzed data; KhM conducted research and had primary responsibility for final content. All authors read and approved the final manuscript.

\section{Funding}

None.

\section{Availability of data and materials}

The data are not publicly available due to containing information that could compromise the privacy of research participants.

\section{Ethics approval and consent to participate}

Ethics approval for the study protocol was granted by The Human Ethics Committee of Tehran University of Medical Sciences (Grant ID: IR.TUMS.VCR. REC1395.1046). All participants signed written informed consent forms.

\section{Consent for publication}

Not Applicable.

\section{Competing interests}

All authors declared that they have no competing interests.

\section{Author details}

${ }^{1}$ Department of Community Nutrition, School of Nutritional Sciences and Dietetics, Tehran University of Medical Sciences (TUMS), Tehran, P.O. Box: 14155-6117, Iran. ${ }^{2}$ Department of Urology, Sina Hospital, Tehran University of Medical Sciences, Tehran, Iran. ${ }^{3}$ Department of Epidemiology and Biostatistics, School of Public Health, Tehran University of Medical Sciences, Tehran, Iran

Received: 25 March 2020 Accepted: 25 July 2020

Published online: 08 August 2020

\section{References}

1. Li Y, Zhang J, Liu H, et al. Curcumin ameliorates glyoxylate-induced calcium oxalate deposition and renal injuries in mice. Phytomedicine. 2019;61:152861.

2. Fink HA, Akornor JW, Garimella PS, et al. Diet, fluid, or supplements for secondary prevention of nephrolithiasis: a systematic review and metaanalysis of randomized trials. Eur Urol. 2009:56(1):72-80.

3. Littlejohns TJ, Neal NL, Bradbury KE, Heers H, Allen NE, Turney BW. Fluid intake and dietary factors and the risk of incident kidney stones in UK Biobank: a population-based prospective cohort study. European urology focus 2019
4. Ong CN. Minerals from drinking water: Bioavailability for various world populations and health implications. Nutrients in Drinking Water 2005:61.

5. Yagisawa T, Chandhoke PS, Fan J. Metabolic risk factors in patients with first-time and recurrent stone formations as determined by comprehensive metabolic evaluation. Urology. 1998;52(5):750-5.

6. Grases F, Melero G, Costa-Bauza A, Prieto R, March J. Urolithiasis and phytotherapy. Int Urol Nephrol. 1994;26(5):507-11.

7. Khan SR. Reactive oxygen species, inflammation and calcium oxalate nephrolithiasis. Translational Androl Urol. 2014;3(3):256.

8. Bo S, Durazzo M, Guidi S, et al. Dietary magnesium and fiber intakes and inflammatory and metabolic indicators in middle-aged subjects from a population-based cohort. Am J Clin Nutri. 2006;84(5):1062-9.

9. Chrysohoou C, Panagiotakos DB, Pitsavos C, Das UN, Stefanadis C. Adherence to the Mediterranean diet attenuates inflammation and coagulation process in healthy adults: the ATTICA Study. J Am Coll Cardiol. 2004:44(1):152-8.

10. Upritchard JE, Sutherland W, Mann JI. Effect of supplementation with tomato juice, vitamin $\mathrm{E}$, and vitamin C on LDL oxidation and products of inflammatory activity in type 2 diabetes. Diab Care. 2000;23(6):733-8.

11. Neale E, Batterham M, Tapsell LC. Consumption of a healthy dietary pattern results in significant reductions in C-reactive protein levels in adults: a meta-analysis. Nutri Res. 2016;36(5):391-401.

12. Esmaillzadeh A, Kimiagar M, Mehrabi Y, Azadbakht L, Hu FB, Willett WC. Dietary patterns and markers of systemic inflammation among Iranian women. J Nutri. 2007;137(4):992-8.

13. Mohseni R, Mohseni F, Alizadeh S, Abbasi S. The Association of Dietary Approaches to Stop Hypertension (DASH) Diet with the risk of colorectal cancer: a meta-analysis of observational studies. Nutrition and cancer 2019:1-13.

14. Alizadeh S, Djafarian K, Alizadeh M, Shab-Bidar S. The relation of healthy and Western dietary patterns to the risk of endometrial and ovarian cancers: a systematic review and meta-analysis. Int J Vitamin Nutrition Res. 2019.

15. Alizadeh S, Shab-Bidar S, Mohtavinejad N, Djafarian K. A posteriori dietary patterns and risk of pancreatic and renal cancers. Nutrition \& Food Science 2017.

16. Mohseni R, Abbasi S, Mohseni F, Rahimi F, Alizadeh S. Association between dietary inflammatory index and the risk of prostate cancer: a meta-analysis. Nutr Cancer. 2019;71(3):359-66.

17. Shivappa N, Steck SE, Hurley TG, et al. A population-based dietary inflammatory index predicts levels of C-reactive protein in the seasonal variation of blood cholesterol study (SEASONS). Public Health Nutrition. 2014;17(8):1825-33.

18. Xu H, Sjögren P, Ärnlöv J, et al. A proinflammatory diet is associated with systemic inflammation and reduced kidney function in elderly adults. J Nutri. 2015:145(4):729-35.

19. Esfahani FH, Asghari G, Mirmiran P, Azizi F. Reproducibility and relative validity of food group intake in a food frequency questionnaire developed for the Tehran lipid and glucose study. J Epidemiol. 2010;20(2):150-8.

20. Shivappa N, Steck SE, Hurley TG, Hussey JR, Hébert JR. Designing and developing a literature-derived, population-based dietary inflammatory index. Public Health Nutri. 2014;17(8):1689-96.

21. Bondonno NP, Blekkenhorst $L C$, Bird $A L$, et al. Dietary inflammatory index and the aging kidney in older women: a 10-year prospective cohort study. Eur J Nutri. 2019:1-11.

22. Maddahi NS, Mirzaei K, Aghamir SMK, Modaresi SS, Yekaninejad MS. Major Dietary Patterns and kidney stone formation among Iranian men. J Nutri Sci Dietetics. 2017:11-17.

23. Moghaddam MB, Aghdam FB, Jafarabadi MA, Allahverdipour $\mathrm{H}$, Nikookheslat SD, Safarpour S. The Iranian version of international physical activity questionnaire (IPAQ) in Iran: content and construct validity, factor structure, internal consistency and stability. World Appl Sci J. 2012;18(8):1073-80

24. Trinchieri A, Mandressi A, Luongo P, Longo G, Pisani E. The influence of diet on urinary risk factors for stones in healthy subjects and idiopathic renal calcium stone formers. Br J Urol. 1991;67(3):230-6.

25. Rouhani MH, Najafabadi MM, Surkan PJ, Esmaillzadeh A, Feizi A, Azadbakht L. Dietary inflammatory index and its association with renal function and progression of chronic kidney disease. Clin Nutri ESPEN. 2019;29:237-41. 
26. Noori N, Honarkar E, Goldfarb DS, et al. Urinary lithogenic risk profile in recurrent stone formers with hyperoxaluria: a randomized controlled trial comparing DASH (Dietary Approaches to Stop Hypertension)-style and low-oxalate diets. Am J Kidney Dis. 2014;63(3):456-63.

27. Leone A, Fernández-Montero A, de la Fuente-Arrillaga C, et al. Adherence to the Mediterranean dietary pattern and incidence of nephrolithiasis in the Seguimiento Universidad de Navarra Follow-up (SUN) cohort. Am J Kidney Dis. 2017;70(6):778-86.

28. Saneei P, Hashemipour M, Kelishadi R, Esmaillzadeh A. The Dietary Approaches to Stop Hypertension (DASH) diet affects inflammation in childhood metabolic syndrome: a randomized cross-over clinical trial. Ann Nutr Metab. 2014;64(1):20-7.

29. Hsu C-C, Jhang H-R, Chang W-T, et al. Associations between dietary patterns and kidney function indicators in type 2 diabetes. Clin Nutr. 2014;33(1):98-105.

30. Duda MK, O'Shea KM, Tintinu A, et al. Fish oil, but not flaxseed oil, decreases inflammation and prevents pressure overload-induced cardiac dysfunction. Cardiovasc Res. 2009;81(2):319-27.
31. Åsgård R, Rytter E, Basu S, Abramsson-Zetterberg L, Möller L, Vessby B. High intake of fruit and vegetables is related to low oxidative stress and inflammation in a group of patients with type 2 diabetes. Scand J Food Nutri. 2007;51(4):149-58.

32. Wood LG, Shivappa N, Berthon BS, Gibson PG, Hebert JR. Dietary inflammatory index is related to asthma risk, lung function and systemic inflammation in asthma. Clin Exp Allergy. 2015;45(1):177-83.

33. Hodge A, Bassett J, Shivappa N, et al. Dietary inflammatory index, Mediterranean diet score, and lung cancer: a prospective study. Cancer Causes Control. 2016;27(7):907-17.

34. Wirth MD, Hébert JR, Shivappa N, et al. Anti-inflammatory dietary inflammatory INDEX scores are associated with healthier scores on other dietary indices. Nutri Res. 2016;36(3):214-9.

\section{Publisher's Note}

Springer Nature remains neutral with regard to jurisdictional claims in published maps and institutional affiliations.
Ready to submit your research? Choose BMC and benefit from:

- fast, convenient online submission

- thorough peer review by experienced researchers in your field

- rapid publication on acceptance

- support for research data, including large and complex data types

- gold Open Access which fosters wider collaboration and increased citations

- maximum visibility for your research: over $100 \mathrm{M}$ website views per year

At BMC, research is always in progress.

Learn more biomedcentral.com/submissions 